\title{
A POLÍTICA EDUCACIONAL NA DÉCADA 2010 A 2020: análise de publicações
}

\author{
Jefferson Mainardes' \\ Silvana Stremel2
}

\section{RESUMO}

Este artigo analisa as principais temáticas abordadas em dossiês e seções temáticas de periódicos brasileiros, no período de 2010 a 2020. Foram selecionados 11 periódicos especializados de Política Educacional e outros 5 não especializados. Concluiu-se que foram publicados 112 dossiês ou seções temáticas sobre temas relacionados à Política Educacional. $O$ artigo indica as temáticas presentes e ausentes e apresenta algumas comparações com temáticas abordadas em periódicos de língua inglesa. Argumenta-se que os periódicos brasileiros deram relevância a temáticas cruciais da Política Educacional da década de 2010 a 2020 cumprindo, desse modo, o papel das revistas acadêmico-científicas que é o de trazer à tona questões de várias ordens, incluindo questões e problemas da conjuntura atual.

Palavras-chave: Política Educacional. Periódicos científicos. Pesquisa em Educação.

\section{EDUCATION POLICY IN THE 2010-2020 PERIOD:}

\section{an analysis of publications}

\begin{abstract}
This paper analyzes the main themes addressed in dossiers and Special Issues of Brazilian journals in the 2010-2020 period. Sixteen journals were selected, out of which 11 specialized in Education Policy, while the other 5 were not specialized. Our results showed that 112 texts addressing themes related to education policy were published. We also indicate the themes approached and those that were absent from the publications, making some comparisons with themes addressed in journals published in English. We point out that Brazilian journals focused on crucial themes regarding education policy in the 2010-2020 decade, thus, playing the important role
\end{abstract}

1 Doutor em Educação, Institute of Education - University of London. Professor da Universidade Estadual de Ponta Grossa (UEPG). Programa de Pós-Graduação em Educação da UEPG. Líder do Grupo de Pesquisa Políticas Educacionais e Práticas Educativas (GPPEPE). Bolsista de Produtividade em Pesquisa do CNPq. Orcid iD: https://orcid.org/0000-0003-04018112. E-mail:jefferson.m@uol.com.br

2 Doutora em Educação, Universidade Estadual de Ponta Grossa (UEPG); Professora da Universidade Tecnológica Federal do Paraná (UTFPR) e do Programa de Pós-Graduação em Educação da Universidade Federal do Paraná (PPGE-UFPR). Orcid iD: http://orcid.org/00000002-31 10-2005. E-mail: silvanastremel@gmail.com 
of academic-scientific journals that is to raise a wide variety of issues and problems of the current context.

Keywords: Education policy. Scientific journals. Education research.

\section{POLÍTICA EDUCATIVA EN LA DÉCADA 2010-2020: análisis de publicaciones}

\section{RESUMEN}

Este artículo analiza los principales temas tratados en los dosieres y secciones temáticas de las revistas brasileñas, en el periodo de 2010 a 2020. Se seleccionaron once revistas especializadas en Política Educativa y otras 5 no especializadas. Se concluyó que se publicaron 112 dosieres o secciones temáticas sobre temas relacionados con la Política Educativa. El artículo indica los temas presentes y ausentes y presenta algunas comparaciones con temas abordados en revistas en idioma inglés. Se argumenta que las revistas brasileñas dieron importancia a temas cruciales de la Política Educativa de 2010 a 2020, cumpliendo así el rol de las revistas académico-científicas, que consiste en sacar a la luz temas de diversa índole, incluyendo cuestiones y problemas de la situación actual.

Palabras clave: Política educativa. Revistas científicas. Investigación en Educación.

\section{INTRODUÇÃO}

O objetivo deste artigo é analisar as principais temáticas abordadas em dossiês e sessões temáticas publicadas na década de 2010 a 2020, em revistas especializadas do campo da Política Educacional, bem como em revistas da área de Educação que publicam dossiês e artigos relacionados ao campo da Política Educacional. A opção pela análise de temas de dossiês dos periódicos selecionados deve-se à compreensão de que os periódicos científicos são espaços privilegiados para a disseminação e socialização de pesquisas, de forma mais ágil e com capacidade para atingir um significativo número de leitores. Além disto, a análise das temáticas de dossiês e seções temáticas pode ser um indício importante para a identificação das principais políticas, interesses e abordagens do período em questão. 


\section{REFERENCIAL TEÓRICO}

A partir do conceito de campo de Pierre Bourdieu, consideramos a Política Educacional como um campo acadêmico abrangente, completo, multifacetado e em permanente construção. Como campo acadêmico, começa a emergir a partir da década de 1960, tendo como antecedentes os estudos sobre a situação do ensino no país e sobre Administração Escolar, Administração Educacional e Educação Comparada. Esse campo desenvolveu-se como produto de condições históricas e sociais, por meio da expansão de publicações sobre política educacional; da criação de disciplinas na Graduação; da criação de linhas e grupos de pesquisa na PósGraduação; da criação de associações científicas e grupos de trabalho dentro de associações; da criação de periódicos científicos especializados; da criação de redes de pesquisa; da realização de eventos científicos específicos de políticas educacionais, bem como pelas ações e tentativas de intervenções dos pesquisadores do campo no próprio processo de formulação de políticas. A partir da década de 1990, o campo adquire maior autonomia e legitimação, e o contexto atual indica que, no Brasil, o campo acadêmico da política educacional encontra-se em fase de expansão e busca de consolidação. (STREMEL, 2016; STREMEL; MAINARDES, 2018).

O conceito de campo refere-se aos diferentes espaços da prática social. Lahire (2017) assim sintetiza o conceito de campo na teoria de Bourdieu:

a) Campo é um espaço estruturado de posições ocupadas pelos diferentes agentes do campo. As práticas e estratégias dos agentes só se tornam compreensíveis se forem relacionadas às suas posições no campo;

b) Campo é um microcosmo incluído no macrocosmo constituído pelo espaço social global (nacional, ou, mais raramente, internacional);

c) Cada campo possui regras de jogo e desafios específicos. Esse espaço é um espaço de lutas, uma arena onde está em jogo uma 
concorrência ou competição entre os agentes que ocupam as diversas posições;

d) O objetivo dessas lutas reside na apropriação de capital específico de cada campo e/ou a redefinição desse capital;

e) Esse capital é desigualmente distribuído no seio do campo. Por conseguinte, existem, nele, dominantes e dominados;

f) A distribuição desigual do capital determina a estrutura do campo que é definido, portanto, pelo estado de uma relação de forças históricas entre as forças (agentes e instituições) em confronto no campo;

g) Em luta uns contra os outros, todos os agentes de um campo têm, contudo, interesse que o campo exista. Eles, mantem, portanto, uma "cumplicidade objetiva" para além das lutas que os opõem;

h) A cada campo corresponde um habitus (sistema de disposições incorporadas) próprio do campo. Apenas os que tiverem incorporado o habitus próprio do campo estão em condições de disputar o jogo e de acreditar na importância dele;

i) Todo campo possui uma autonomia relativa: as lutas que se desenrolam em seu interior têm uma lógica própria, mesmo que o resultado das lutas externas ao campo pese fortemente no desfecho das relações de forças internas.

Com base em Bourdieu, entendemos que um campo precisa de agentes, instituições, ideias e interesses específicos que lhe dê sustentação e legitimação. Gómez Campo e Tenti Fanfani (1989), fundamentados em Bourdieu, consideram que a estruturação dos campos é constituída pelas associações profissionais mediante as suas revistas, periódicos, reuniões técnicas e científicas etc. Dessa forma, os periódicos científicos e suas publicações são parte da estrutura de um campo (agentes), a partir dos quais é possível mapear os capitais específicos em jogo (debates, temáticas, concepções etc).

A Política Educacional como um campo abrangente, engloba uma série de objetos de estudo: 
a) Estudos de natureza teórica: Estado e mudanças no papel do Estado, Neoliberalismo, globalização, relação público-privado, mudanças no mundo do trabalho, modos de governança, gerencialismo, redes de políticas, fundamentos teórico-metodológicos da pesquisa sobre políticas educacionais, epistemologias da política educacional, entre outros;

b) Análise de políticas educacionais específicas;

C) Políticas educacionais e gestão (educacional e escolar);

d) Legislação educacional;

e) Financiamento da educação;

f) Políticas curriculares;

g) Políticas voltadas ao trabalho docente (formação, valorização, carreira etc);

h) Questões relacionadas às demandas educacionais, oferta, acesso. (MAINARDES, 2018).

Como explica Souza $(2019,2021)$, no campo da política e gestão da educação, a conjuntura político-educacional é fundamental na delimitação dos objetos de estudo (agenda de pesquisa). Os pesquisadores deste campo, em geral, buscam acompanhar os movimentos da Política Educacional seja no nível mais amplo ou no nível local.

\section{METODOLOGIA}

Para a definição do corpus foram selecionadas as seguintes revistas:

a) Ensaio: Avaliação e Políticas Públicas em Educação;

b) Fineduca;

c) Jornal de Políticas Educacionais;

d) Políticas Educativas;

e) Revista Brasileira de Política e Administração da Educação (ANPAE);

f) Revista de Administração Educacional; 
g) Revista de Estudios Teóricos y Epistemológicos en Políticas Educativas;

h) Revista Educação Básica em Foco - ANPAE;

i) Revista Educação e Políticas em Debate;

j) Revista On Line de Política e Gestão Educacional;

k) REGAE - Revista de Gestão e Avaliação Educacional;

I) Cadernos de Pesquisa;

m) Educação \& Sociedade;

n) Educar em Revista;

o) Educação em Revista;

p) Práxis Educativa.

As 11 primeiras são revistas mais diretamente relacionadas ao campo da Política e Gestão da Educação e as cinco últimas foram incluídas pelo fato de serem revistas reconhecidas na área de Educação e que publicam dossiês e seções temáticas. Trata-se, portanto, de um recorte de revistas, que está distante de oferecer um panorama das publicações brasileiras. O período consultado foi de 2010 a 2020. Os dados foram coletados em maio e junho de 2021 e registrados em planilhas. Os dados coletados foram: nome da revista, título do dossiê, seção temática ou similar, cujo tema fosse relacionado à Política e Gestão da Educação, nome dos responsáveis pelo dossiê ou seção temática, número total de artigos e autoria (artigos de autores brasileiros, de autores estrangeiros, de autores estrangeiros em coautoria com brasileiros).

A Tabela 1 apresenta o total de dossiês ou seções temáticas e os demais dados coletados. Observa-se que um número significativo de dossiês ou seções temáticas foram publicados (112), com um total de 961 artigos, sendo 806 de autores brasileiros, 148 de autores estrangeiros e sete de autores brasileiros em parceira com autores estrangeiros. As revistas com maior número de dossiês publicados foram: Revista Educação e Políticas em 
Debate (20), Políticas Educativas (19), Revista Brasileira de Política e Administração da Educação (14) e Educação \& Sociedade (13). Duas revistas incluídas no levantamento não publicaram dossiês ou seções temáticas (REGAE - Revista de Gestão e Avalição Educacional e Ensaio: Avaliação e Políticas Públicas em Educação).

TABELA 1 - Quantidade de dossiês, artigos e resenhas relacionados à Política Educacional (2010-2020)

\begin{tabular}{|c|c|c|c|c|c|c|}
\hline Periódico & $\begin{array}{c}\text { Total de dossiês } \\
\text { de Política } \\
\text { Educacional }\end{array}$ & $\begin{array}{l}\text { Total } \\
\text { de } \\
\text { artigos }\end{array}$ & $\begin{array}{l}\text { Total de } \\
\text { artigos de } \\
\text { autores } \\
\text { brasileiros }\end{array}$ & $\begin{array}{l}\text { Total de } \\
\text { artigos de } \\
\text { autores } \\
\text { estrangeiros }\end{array}$ & $\begin{array}{c}\text { Total de } \\
\text { artigos de } \\
\text { autores } \\
\text { estrangeiros } \\
\text { em } \\
\text { coautoria } \\
\text { com } \\
\text { brasileiros }\end{array}$ & $\begin{array}{l}\text { Total de } \\
\text { resenhas }\end{array}$ \\
\hline $\begin{array}{l}\text { Ensaio: Avaliação e } \\
\text { Políticas Públicas } \\
\text { em Educação }\end{array}$ & $*$ & * & $*$ & * & $*$ & $*$ \\
\hline $\begin{array}{l}\text { FINEDUCA - Revista } \\
\text { de Financiamento } \\
\text { da Educação }\end{array}$ & 2 & 18 & 18 & 0 & 0 & 1 \\
\hline $\begin{array}{l}\text { Jornal de Políticas } \\
\text { Educacionais }\end{array}$ & 4 & 37 & 33 & 4 & 0 & 0 \\
\hline Políticas Educativas & 19 & 82 & 48 & 33 & 1 & 0 \\
\hline $\begin{array}{lr}\text { Revista Brasileira de } \\
\text { Política } & \text { e } \\
\text { Administração } & \text { da } \\
\text { Educação } & \\
\end{array}$ & 14 & 125 & 110 & 14 & 1 & 0 \\
\hline $\begin{array}{ll}\text { Revista } & \text { de } \\
\text { Administração } & \\
\text { Educacional } & \\
\end{array}$ & 1 & 10 & 10 & 0 & 0 & 0 \\
\hline $\begin{array}{l}\text { Revista de Estudios } \\
\text { Teóricos y } \\
\text { Epistemológicos en } \\
\text { Política Educativa } \\
\end{array}$ & 7 & 30 & 15 & 15 & 0 & 0 \\
\hline $\begin{array}{l}\text { Revista Educação } \\
\text { Básica em Foco - } \\
\text { ANPAE }\end{array}$ & 4 & 103 & 103 & 0 & 0 & 0 \\
\hline $\begin{array}{l}\text { Revista Educação e } \\
\text { Políticas em Debate }\end{array}$ & 20 & 168 & 165 & 3 & 0 & 1 \\
\hline $\begin{array}{l}\text { Revista on line de } \\
\text { Política e Gestão } \\
\text { Educacional }\end{array}$ & 8 & 106 & 95 & 10 & 1 & 0 \\
\hline $\begin{array}{lr}\text { REGAE - Revista de } \\
\text { Gestão } \\
\text { Avaliação } \\
\text { Educacional }\end{array}$ & * & $*$ & * & $*$ & * & $*$ \\
\hline $\begin{array}{ll}\text { Cadernos } & \text { de } \\
\text { Pesquisa } & \\
\end{array}$ & 8 & 39 & 26 & 13 & 0 & 0 \\
\hline $\begin{array}{ll}\text { Educação } & \& \\
\text { Sociedade } & \\
\end{array}$ & 13 & 108 & 71 & 34 & 3 & 0 \\
\hline Educar em Revista & 6 & 54 & 41 & 12 & 1 & 0 \\
\hline Educação $\quad$ em & 2 & 12 & 9 & 3 & 0 & 0 \\
\hline
\end{tabular}




\begin{tabular}{l|c|c|c|c|c|c}
\hline Revista & & & & & & \\
\hline Práxis Educativa & 4 & 69 & 62 & 7 & 0 & 2 \\
\hline TOTAL & $\mathbf{1 1 2}$ & $\mathbf{9 6 1}$ & $\mathbf{8 0 6}$ & $\mathbf{1 4 8}$ & $\mathbf{7}$ & $\mathbf{4}$ \\
\hline
\end{tabular}

Fonte: Elaborada pelos autores.

Nota: $\left({ }^{*}\right)$ Não publicou dossiês no período.

\section{ANÁLISE DE DADOS}

A partir do levantamento e da catalogação dos dossiês e seções temáticas publicados nas revistas selecionadas, os dados foram categorizados, conforme Tabela 2.

Tabela 2 - Temáticas abordadas nos dossiês e seções temáticas

\begin{tabular}{l|c}
\hline \multicolumn{1}{c|}{ Temática } & Total \\
\hline Políticas de Educação Superior & 7 \\
\hline Políticas de Inclusão e diversidade & 7 \\
\hline Políticas de privatização da educação & 5 \\
\hline Políticas de regulação (accountability, responsabilização) & 5 \\
\hline $\begin{array}{l}\text { Questões teórico-epistemológicas e conceituais na pesquisa em Política } \\
\text { Educacional (Estudos epistemológicos, redes, ciclo de políticas, Grupos de } \\
\text { Pesquisa, Pesquisa em Política) }\end{array}$ & 5 \\
\hline Constituição Federal (25 anos, 30 anos) & 4 \\
\hline Políticas de Igualdade Racial & 4 \\
\hline $\begin{array}{l}\text { Políticas Públicas em Educação (desafios, políticas conservadoras, } \\
\text { educação no cenário político-econômico mundial) }\end{array}$ & 4 \\
\hline Formação de inicial e continuada profissionais da Educação & 4 \\
\hline $\begin{array}{l}\text { Gestão educacional (debates contemporâneos e gestão em sistemas } \\
\text { municipais) }\end{array}$ & 4 \\
\hline Gestão da escola pública e gestão democrática da escola & 4 \\
\hline $\begin{array}{l}\text { O campo da Política Educacionais em países da América Latina (Chile, } \\
\text { México, Argentina, Brasil) }\end{array}$ & 4 \\
\hline Políticas do Ensino Médio & 4 \\
\hline $\begin{array}{l}\text { Financiamento da Educação (PEC 24l/55 e remuneração de professores } \\
\text { no contexto do Fundef e PSPN }\end{array}$ & 3 \\
\hline Políticas de Currículo & 3 \\
\hline $\begin{array}{l}\text { Políticas de Planejamento Educacional no Brasil, Conferência Nacional de } \\
\text { Educação e PNE }\end{array}$ & 3 \\
\hline Políticas de avaliação externa e qualidade da educação & 3 \\
\hline Políticas de Educação a Distância & 3 \\
\hline Políticas para a Educação Infantil & 3 \\
\hline $\begin{array}{l}\text { Questões conceituais: Socialização política e Educação } \\
\text { comportamento político }\end{array}$ & 2 \\
\hline Nova gestão Pública & 2 \\
\hline Políticas Educacionais - trabalho docente & 2 \\
\hline Homeschooling & 1 \\
\hline
\end{tabular}




\begin{tabular}{l|c}
\hline As políticas educacionais dos novos governos na América Latina & 1 \\
\hline Políticas educacionais e a resistência estudantil & 1 \\
\hline Movimentos Sociais e Transformações do Ativismo Contemporâneo & 1 \\
\hline 50 anos pós Golpe Militar & 1 \\
\hline Globalização e os desafios para os sistemas nacionais: agenda & 1 \\
internacional e práticas educacionais nacionais & 1 \\
\hline Público e privado & 1 \\
\hline Militarização da escola pública & 1 \\
\hline Âmbito escolar e suas compreensões: políticas públicas e seus \\
desdobramentos & 1 \\
\hline Políticas práticas de saúde no âmbito escolar & 1 \\
\hline Os desafios políticos para a educação e democracia na América Latina & 1 \\
\hline Vulnerabilidades Sociais, Inclusão Social e Políticas Educativas & 1 \\
\hline Sentidos e Ideias em torno da Educação e do Educativo & 1 \\
\hline $\begin{array}{l}\text { Gestão Democrática e a Emancipação: interfaces entre políticas } \\
\text { públicas, sistemas educacionais e gestão escolar }\end{array}$ & 1 \\
\hline Políticas educativas e luta cultural & 1 \\
\hline Estado e sociedade civil em Gramsci, políticas de ensino médio e & 1 \\
tecnologias educacionais digitais na escola básica & 1 \\
\hline Políticas públicas no sistema carcerário e socioeducativo do Brasil & 1 \\
\hline Políticas de educação escolar em ambientes hospitalares & 1 \\
\hline Políticas de leitura e do livro para a Educação no Brasil: contribuições \\
históricas e atualidades & 1 \\
\hline Políticas de Educação do Campo & 1 \\
\hline Políticas públicas de educação em tempo integral: Desafios atuais & 1 \\
\hline $\begin{array}{l}\text { Implementação de Políticas Educacionais: debates teóricos e } \\
\text { problematizações }\end{array}$ & 1 \\
\hline Direito à educação, políticas educacionais e princípios de justiça & 1 \\
\hline Desigualdades educacionais e pobreza & 1 \\
\hline Educação em tempos de pandemia & 1 \\
\hline Alfabetização e Letramento & 1 \\
\hline Educação, democracia e diferença & 1 \\
\hline Fonte: & 1 \\
\hline
\end{tabular}

Fonte: Elaborada pelos autores.

De modo geral, observa-se que as revistas especializadas do campo acadêmico da Política Educacional e outras que publicaram dossiês/seções temáticas cumprem o importante papel de estimular o debate sobre as políticas educacionais emergentes na conjuntura brasileira e latinoamericana.

A primeira constatação é que houve uma significativa dispersão temática nos dossiês e seções temáticas publicados. Os temas mais presentes foram: Políticas de Educação Superior, Políticas de inclusão e diversidade, Políticas de privatização da educação, Políticas de regulação, 
Questões teórico-epistemológicas da pesquisa em Política Educacional, Constituição Federal e educação, Políticas de igualdade racial, Políticas públicas de educação, Formação inicial e continuada de profissionais da educação, Gestão educacional (debates contemporâneos e gestão em sistemas municipais), Gestão da escola pública e gestão democrática da escola, O campo da Política Educacional em países da América Latina (Chile, México Argentina, Brasil) e Políticas do Ensino Médio. Como já afirmado, trata-se de um campo abrangente e complexo. As temáticas dos dossiês estão relacionadas a políticas e temáticas bastante presentes na década de 2010-2020. Trata-se de um período bastante agitado em termos políticos, econômicos e sociais que envolvem o momento final do Governo Lula, os mandatos da Presidenta Dilma Roussef, o mandato de Michel Temer e, finalmente, a primeira parte do Governo Bolsanaro. De modo geral, observa-se que os dossiês/seções temáticas do período de 2010 a 2016 discutiam políticas do período, sendo parte significativa com análises críticas. Nos anos finais da década, diversos dossiês, acompanhando as políticas conservadoras e retrógradas propostas, priorizaram, entre outros temas, aqueles altamente atuais, tais como Políticas conservadoras na Educação Básica, Militarização, Homeschooling, pandemia da Covid-19 etc. As revistas possuem condição de responder mais agilmente às demandas que surgem no contexto da Política Educacional, ou seja, questões relacionadas à conjuntura política. Apesar disso, foram poucas as revistas que conseguem uma rápida articulação para atender temáticas mais urgentes.

Embora tenham sido publicados diversos dossiês sobre temáticas mais diretamente relacionadas às políticas no contexto das escolas, destacou-se a Revista Educação Básica em Foco - ANPAE, que publicou dossiês sobre: Educação em tempos de pandemia: vozes dos sujeitos da educação Básica, Financiamento da Educação Básica no contexto de pandemia da COVID-19: desafios para a garantia do direito à educação, Gestão democrática na escola: alternativas em construção, Alfabetização e letramento: desafios em tempos de pandemia. Isto indica que um dos desafios para o campo da Política Educacional é buscar atender questões 
mais amplas, por meio de problematizações e teorizações, bem como questões teórico-práticas relacionadas às demandas da Educação Básica. Há também inúmeras possibilidades de desenvolvimento de estudos que combinem os planos macro e micro, como propõe Power (2006).

Os dados coletados a partir dos dossiês e seções temáticas indicam que foram reduzidos os espaços para a publicações de reflexões e problematizações mais diretamente relacionados a questões teóricoepistemológicas da pesquisa em Política Educacional. Conforme dados da Tabela 2 , os dossiês e seções temáticas relacionados nessas categorias foram os seguintes:

a) Estudos Epistemológicos da Política Educacional (Práxis Educativa);

b) Redes políticas; Ciclo de Políticas e Teoria da atuação; Campo da Política Educacional em países da América Latina - Chile, México, Argentina e Brasil (Revista de Estudios Teóricos y Epistemológicos en Políticas Educativas);

c) Grupos de Pesquisa de Política Educacional; Pesquisa em Política Educacional (Jornal de Políticas Educacionais);

d) Socialização política; Educação e comportamento político (Educação \& Sociedade);

e) Educação, democracia e diferença (Cadernos de Pesquisa).

Do total de 112 dossiês/seções temáticas, apenas 12 referem-se a essas questões $(10,7 \%)$. As pesquisas e publicações que tematizam a própria pesquisa em Política Educacional e seus fundamentos teóricoepistemológicos são fundamentais, pois podem apresentar balanços críticos e avaliações das pesquisas do próprio campo.

A temática sobre o financiamento da educação é fundamental na educação brasileira. Foram identificados apenas três dossiês (dois da Fineduca e um da Revista Brasileira de Política e Administração da Educação). Deve-se levar em consideração que a principal revista da área (Fineduca - Revista de Financiamento da Educação), desde 2011, publica artigos sobre a temática. Contudo, no formato de dossiê, publicou apenas 
dois, fazendo com que a temática do financiamento não aparecesse de forma mais significativa nos limites deste artigo.

Observa-se também que alguns temas atuais e polêmicos parecem ter sido pouco tematizados em dossiês e seções temáticas, como é o caso da avaliação em larga escala e políticas curriculares. Deve-se levar em consideração que estas temáticas foram tratadas de forma mais extensiva em outros canais de divulgação científica, ou seja, em revistas especializadas (avaliação e currículo). Além disto, as revistas Teias, eCurriculum e Currículo Sem Fronteiras, com a participação de pesquisadores da Associação Brasileira de Currículo ( $A B d C)$, publicaram diversos dossiês sobre questões curriculares (BNCC, Reforma do Ensino Médio etc).

É possível estabelecer algumas comparações entre os debates e temáticas presentes nas publicações brasileiras e em publicações estrangeiras de língua inglesa, tais como: coletâneas especializadas e revistas como Journal of Education Policy, Critical Studies in Education, British Journal of Sociology of Education, Other Education (Journal of Education Alternatives), Educational Policy (SAGE), Arquivos Analíticos de Políticas Educativas.

A primeira comparação refere-se ao debate sobre a mobilidade de políticas e a etnografia de redes. Junemann, Ball e Santori (2018) indicam que novas maneiras de organizar e fornecer políticas e serviços públicos estão sendo introduzidas. Relações hierárquicas e burocráticas estão sendo substituídas por relações heterárquicas e empresariais ou de mercado, indicando uma mudança para a governança de rede (RHODES, 1997 apud JUNEMANN; BALL; SANTORI, 2018). Novos atores estão "fazendo" política, de novas maneiras, em novos lugares - unidos em redes sociais complexas e em evolução. Essas redes exigem de pesquisadores novos métodos e sensibilidades, tais como a etnografia de redes. As mobilidades globais do fluxo de políticas podem ser identificadas a partir da análise de lugareschave, nós ou infraestruturas importantes (conversas, reuniões presenciais, conferências etc). O método da etnografia de rede, com um foco específico sobre o "onde" da política (eventos, reuniões e conferências e o 
trabalho de persuasão, reiteração, recrutamento e circulação de narrativas e histórias que acontecem nesses lugares), mostra-se relevante para a compreensão das mobilidades políticas. Autores como Ball (2012), Ball e Junemann (2012) sugerem que a etnografia de redes é adequada para especificar as trocas e transações entre os participantes das redes globais de políticas educacionais e os papéis, ações, motivações, discursos, e recursos dos diferentes atores envolvidos. Como uma versão da prática etnográfica, as pesquisas de etnografia de rede aderem as quatro principais características da pesquisa qualitativa indicada por Burgess (1985 apud JUNEMANN; BALL; SANTORI, 2018), a saber: a) o pesquisador trabalha em um ambiente natural; b) os estudos podem ser planejados e re-planjeados; c) a pesquisa se preocupa com processos e significados sociais; e) dados, coleta e análise de dados ocorrem simultaneamente. A etnografia de rede oferece oportunidades metodológicas para acompanhar o foco das mobilidades políticas e agenciamento (assemblage) ${ }^{3}$, bem como os desafios que ela apresenta. No Brasil, ainda são poucos os trabalhos que apresentam as bases teóricas e a aplicação da etnografia de redes (e.g. AVELAR; BALL, 2017; AVELAR; NIKITA; BALL, 2018; ROSA; FERREIRA; SILVA, 2020; SHIROMA, 2020; ARAUJO; LOPES, 2021). Isso indica uma necessidade de realização de pesquisas e publicações que fundamentem tais discussões.

Uma segunda possível comparação diz respeito a discussões teóricas que têm sido debatidas em publicações estrangeiras, tais como as contribuições da sociologia crítica das políticas educacionais (critical policy sociology) e do papel dos pesquisadores com relação à problematização e construção de soluções. No Reino, principalmente, a pesquisa sobre políticas educacionais está relacionada à Sociologia da Educação. Em termos gerais, a sociologia das políticas educacionais significa a utilização das teorias e

\footnotetext{
3 De acordo com Wise (2005, p. 77). "assemblage (agenciamento), como é utilizada na obra de Deleuze e Guattari, é um conceito que lida com o jogo de contingência e estrutura, organização e mudança" (p. 77). O termo em francês é agencement, normalmente traduzido como "arranjo", "disposição" ou "encaixar". Youdell (2015) explica que Deleuze e Guattari utilizam as noções de "agrupamentos", "arranjos" e "assemblages" para pensar sobre a multiplicidade de elementos diversificados e móveis que se combinam para constituir formações sociais complexas. Ver também Mainardes (2015).
} 
métodos da Sociologia da Educação para a pesquisa sobre Políticas Educacionais (MAINARDES; ALFERES, 2014). A sociologia das políticas educacionais surgiu no final dos anos 1980, quando um grupo de sociólogos da educação procurou desafiar os modelos de análise empregados na época. Eram sociólogos de universidades do Reino Unido e da Austrália (SAVAGE, 2021).

A maior parte dos pesquisadores que associam seus estudos com a sociologia crítica das políticas educacionais, implícita ou explicitamente, refletem um compromisso com uma política de pesquisa que busca desafiar as estruturas de poder dominantes. Em alguns casos, esses compromissos políticos se estendem ao desenvolvimento de pesquisas que procuram explicitamente inspirar mudanças sociais, políticas ou educacionais. (SAVAGE et al., 2021). No entanto, agendas políticas emancipatórias explícitas nem sempre estão presentes, nem são preferidas, na pesquisa de sociologia crítica das políticas educacionais. Sellar et al. (2014 apud SAVAGE et al., 2021) argumentam que existem diferentes maneiras de entender o que significa "ser crítico", e muitos estudiosos da sociologia crítica das políticas educacionais engajam-se em um tipo diferente de política que não busca articular explicitamente soluções ou visões de um futuro desejado. Esta forma de pesquisa crítica frequentemente envolve estratégias, como: mapear e desempacotar relações e redes de poder, examinar como as formações políticas e sociais são montadas e criticar a construção de soluções/problemas. Essa pesquisa normalmente examina, critica e busca explicar os fenômenos sociais, mas sem estender isso a uma visão específica para a mudança que outros veem como parte integrante do estudo crítico. Seguindo Latour (2004), Savage et al. (2021) consideram que tais estudiosos sinalizam um modo alternativo de crítica e um tipo diferente de disposição crítica, que busca reunir ideias com o objetivo de oferecer aos leitores "arenas" nas quais possam engajarem-se em conversações críticas (LATOUR, 2004 apud SAVAGE et al., 2021, p. 308). Em resumo, há duas importantes formas de crítica: a problematização e a construção de soluções ou alternativas, para os quais Savage et al. (2021, p. 309, tradução nossa) 
concluem que "os processos de construção de soluções são tão limitados quanto os atos de problematização, e igualmente capazes de produzir novas possibilidades de pensar e compreender o mundo". Em outras palavras, ambas as possibilidades possuem limitações e contribuições. Nesse caso, é importante que os pesquisadores do campo da Política Educacional tenham clareza a respeito da sua perspectiva ético-ontoepistemológica ${ }^{4}$, bem como das epistemologias e teorias que fundamentam seus estudos, visto que cada epistemologia ou teoria que adotamos possuem um ethos sociopolítico voltado para a transformação ou para a manutenção/mudança da estrutura e do contexto social.

Uma terceira comparação refere-se ao debate a respeito do que significa a análise crítica de políticas. Molla (2021) indica que embora o termo "crítico" seja bastante empregado, muitas vezes permanece obscuro e pouco explorado nas diferentes vertentes de análise crítica de políticas, tais como: a) a sociologia das políticas educacionais (policy sociology), representada pelas contribuições de Stephen J. Ball, Jenny Ozga; b) a sociologia crítica das políticas educacionais (Trevor Gale); c) a análise crítica das políticas (Michael Apple, Sonya Douglass Horsford, Janelle T. Scott, Gary L. Anderson, Sandra Taylor, John Prunty); d) abordagens críticas à análise de políticas educacionais (Michelle Young e Sarah Diem); e e) Estudos de crítica política (Gerald Grace). Ainda para Molla (2021), a vantagem dos estudos críticos de políticas é que eles colocam "questões específicas de política educacional dentro do quadro mais amplo dos contextos históricos, socioeconômicos e políticos" (p. 4, tradução nossa). Os estudos críticos de políticas reconhecem o valor do rigor metodológico, a contextualizade da política e a posicionalidade do analista de política. (MOLLA, 2021). Molla (2021) explica ainda que criticar não significa mera objeção; ao contrário, significa

[...] problematizar suposições e crenças que sustentam a aparência objetiva da realidade e os sistemas de significados subjetivos associados à representação externa. O objetivo é desmascarar

\footnotetext{
4 A respeito do conceito de ético-ontoepistemologia ver Stetsenko (2021) e Mainardes
} (2021). 
discursos hegemônicos (Gramsci, 1971) que mantém os desfavorecidos conformados com suas condições - expor como a classe dominante instala seus própios valores como senso comum da sociedade como um todo". [...] Portanto, criticar é problematizar enquadramentos e suposições dos processos políticos. (MOLLA, 2021, p. 9-10, tradução nossa).

Na análise de Diem, Young e Sampson (2019), os pesquisadores que empregam abordagens críticas de políticas educacionais tendem a concentrar-se em cinco questões:

1. Preocupação com a diferença entre a retórica da política e a realidade praticada;

2. Preocupação com a política, suas raízes e seu desenvolvimento (por exemplo, como surgiu, que problemas pretendia resolver, como mudou e se desenvolveu ao longo do tempo e seu papel no reforço da cultura dominante);

3. Preocupação com a distribuição de poder, recursos e conhecimento, bem como com a criação de "vencedores" e "perdedores" da política;

4. Preocupação com a estratificação social e o efeito mais amplo que uma determinada política tem nas relações de desigualdade e privilégio. $\mathrm{E}$

5. Preocupação com a natureza de resistência ou envolvimento na política de grupos não dominantes (Young \& Diem, 2017, p. 4). (DIEM; YOUNG; SAMPSON, 2019, p. 6, tradução nossa).

No caso da pesquisa sobre políticas educacionais realizada no Brasil, observamos que a definição do que efetivamente a análise crítica envolve é ainda um pouco vaga, o que demanda esforço de pesquisadores no sentido de aprofundar esse conceito.

Uma quarta comparação refere-se a críticas radicais sobre o papel da educação e da escola. Tais discussões têm sido feitas em revistas internacionais altamente reconhecidas, tais como: British Journal of Sociology of Education, Critical Studies in Education, Other Education, entre outros. De modo geral, estão articuladas às discussões da sociologia crítica de políticas educacionais, como por exemplo as mais recentes publicações de Ball (2020, 2021) e Ball e Collet-Sabé (2021). No artigo "Contra a escola: uma crítica epistemológica", Ball e Collet-Sabé (2021) argumentam que a escola moderna é uma 'intolerável' instituição. Contrariamente às sensibilidades da investigação educacional que procuram mais e/ou melhor escolaridade 
como forma de tornar a educação mais igualitária e inclusiva, os autores posicionam-se, baseando-se em Foucault, "contra a escola europeia moderna como instituição de normalização dentro da qual a igualdade e a inclusão são impossíveis" (BALL; COLLET-SABÉ, 2021, p. 1, tradução nossa). O artigo afirma que é necessário ser "contra" e não "a favor" da escola e abandonar a "perspectiva redentora" da educação e da escola (BALL; COLLET-SABÉ, 2021, p. 1). Os autores propõem a necessidade de pensar a educação diferentemente e fora da escola, a fim de abrir outras possiblidades de "educações", e especificamente como uma atividade ética, uma exploração de limites e uma política de si mesmo. Este discurso de estilo crítico-radical e desconstrucionista em torno de papel da educação e da escola, no entanto, não é novo (LEASK, 2011; LEE, 2014; ALLEN, 2015, 2017) e é o oposto da maior parte das proposições de pesquisadores brasileiros. É possível que, em virtude do contexto político e socioeconômico brasileiro, não seja produtivo, na atual conjuntura, assumir uma posição contrária à educação e à escola, visto que o próprio governo federal e alguns gestores educacionais, ao invés de defende-las, têm as atacado, bem como desmontado o aparato de políticas que, ainda que não fossem totalmente inclusivas e emancipatórias, garantiam oportunidades de acesso e, de alguma forma, a construção de uma qualidade da educação melhor do que havia no passado. Nesse sentido, o que parece mais adequado é utilizar este potencial crítico radical para a análise crítica das políticas atuais, desvelando o seu caráter excludente e sua inadequação para a efetivação dos propósitos de democracia, justiça social e igualdade.

\section{CONSIDERAÇÕES FINAIS}

Neste artigo, apresentamos uma breve análise das principais temáticas e discussões presentes em dossiês e seções temáticas de revistas brasileiras especializadas do campo da Política Educacional e de outras de caráter mais geral. Constatamos que periódicos deram relevância a temáticas 
cruciais da Política Educacional da década de 2010 a 2020 cumprindo, desse modo, o papel das revistas acadêmico-científicas que é o de trazer à tona questões de várias ordens, incluindo questões e problemas da conjuntura atual. A discussão qualificada sobre tais problemas atuais é fundamental para ampliar e subsidiar 0 debate em torno das políticas educacionais. É importante lembrar pelo menos três razões pelas quais o campo da política educacional é altamente complexo. O primeiro, como já afirmado, refere-se ao fato de que se trata de um campo abrangente, complexo, envolvendo inúmeras temáticas relacionadas à política e gestão da educação. O segundo, refere-se ao fato de que a Política Educacional se constitui como um projeto científico e um projeto político. Como projeto científico, necessita oferecer análises e conclusões consistentes, com base em critérios de cientificidade, tais como: objetividade, adequação e verificabilidade. Como projeto político, a pesquisa em política educacional está sempre comprometida em oferecer análises e conclusões socialmente referenciadas e politicamente engajadas, baseadas em critérios de normatividade política, tais como: legitimidade, eficácia em termos de justiça social e igualdade e criticidade. Por último, o campo da Política Educacional desafia os pesquisadores a compreenderem, na medida do possível, tendo em vista a variedade de objetos e abordagens teóricoepistemológicas, a indissociablidade de políticas e práticas. Isto requer análises das políticas e dos contextos nos quais ela é colocada em ação, com seus resultados/efeitos e consequências materiais. Enquanto um aspecto teórico-prático, a Política Educacional, requer além de teorizações e problematizações, intervenções e posicionamentos ativistas transformadores, nos quais pesquisadores e participantes das pesquisas podem articular ações e projetos que resultem em benefícios coletivos.

Há uma significativa literatura que indica que as políticas não são meramente implementadas, mas recontextualizadas no contexto da prática e que as escolas, profissionais da educação e estudantes são também produtores de políticas (BALL, 1994; BALL; MAGUIRE; BRAUN, 2021). Apesar disto, observa-se ainda a imposição de políticas e emprego de estratégias 
de controle, pelo aparelho de Estado, com o objetivo de conseguir que as políticas sejam "implementadas", reduzindo os espaços de autonomia da escola e da ação docente. É importante que os pesquisadores tenham clareza desta realidade para que possam incorporar nas suas análises, as mudanças que têm ocorrido no plano da gestão educacional com relação a uma redução drástica da autonomia da escola e aumento das estratégias de controle do trabalho docente. Simultaneamente, é preciso lutar insistentemente para que as políticas sejam formuladas de modo democrático e participativo, com espaços ampliados e legítimos para o debate de ideias, com a participação dos profissionais da educação, conselhos municipais, sindicatos etc. Em 1994, Ball já criticava o fato de que os contextos (as escolas) precisavam adaptar-se às políticas em vez das políticas serem formulados para e com os contextos. Já se passaram quase 30 anos desta afirmação e estamos convivendo cada vez mais com políticas impostas, autoritárias e com potencial baixíssimo para a construção de uma educação ampliada, de qualidade e socialmente referenciada.

Finalmente, destacamos que o título do prefácio à segunda edição do livro "Como as escolas fazem as políticas" (BALL; MAGUIRE, BRAUN, 2021), escrito por Alice C. Lopes e Elizabeth Macedo (2021), é um significativo convite para assumirmos uma posição enquanto pesquisadores do campo da Política Educacional: "Em defesa das escolas como produtoras de políticas". No contexto da educação brasileira, sugerimos que esta ideia poderia ser ampliada: em defesa das redes públicas como produtoras de políticas; de pesquisadores/as, profissionais da educação, estudantes como produtores de políticas. Argumentamos que a proposição de políticas estreitas, limitadas e centralizadas, por pequenos grupos de poder, interesse e ideologia, não têm potencial para atender as demandas das escolas e do modelo democrático e inclusivo que defendemos. 


\section{REFERÊNCIAS}

ALLEN, A. The cynical educator. Other Education - The Journal of Educational Alternatives, [s. I.], v. 4, n. 1, p. 4-15, 2015.

ALLEN, A. The cynical educator. Leicester: Mayfly, 2017.

ARAUJO, H. G.; LOPES, A. C. Redes políticas de currículo: a atuação da FGV. Práxis Educativa, Ponta Grossa, e2118297, v. 16, p. 1-21, 2021.

AVELAR, M.; BALL, S. J. Mapping new philanthropy and the heterarchical state: the mobilization for the National Learning Standards in Brazil.

International Journal of Educational Development, [s. I.], v. 64, p. 65-73, jan. 2017.

AVELAR, M. NIKITA, D. P.; BALL, S. J. Education policy networks and spaces of 'meetingness': a network ethnography of a Brazilian Seminar. In: ALTINYELKEN, H. K. (ed.). Global education policy and international development: new agendas, issues and policies. London: Bloomsbury, 2018. p. 55-74.

BALL, S. J. Education reform: a critical and post-structural approach. Buckingham: Open University Press, 1994.

BALL, S. J. Global education inc.: new policy networks and the neo-liberal imaginary. London: Routledge, 2012.

BALL, S. J. The errors of redemptive sociology or giving up on hope and despair. British Journal of Sociology of Education, [s. I.], v. 41, n. 6, p. 870-880, 2020.

BALL, S. J. Response: policy? Policy research? How absurd. Critical Studies in Education, [s. l.], v. 62, n. 2, p. 1-7, 2021.

BALL, S. J.; COLLET-SABÉ, J. Against school: an epistemological critique. Discourse: Studies in the Cultural Politics of Education, [s. I.], v. 42, p. 1-15, 2021.

BALL, S. J.; JUNEMANN, C. Networks, New Governance and Education. Bristol: Policy Press, 2012.

BALL, S. J.; MAGUIRE, M.; BRAUN, A. Como as escolas fazem as políticas: atuação em escolas secundárias. 2. ed. Ponta Grossa: UEPG, 2021.

DIEM, S.; YOUNG, M. D.; SAMPSON, C. Where critical policy meets the politics of education: an introduction. Educational Policy, [s. I.], v. 33, n. 1, p. 3-15, jan. 2019. 
GÓMEZ CAMPO, V. M.; TENTI FANFANI, E. Universidad y profesiones: crisis y alternativas. Buenos Aires: Miño y Dávila Editores, 1989.

JUNEMANN, C.; BALL, S. J.; SANTORI, D. On Network(ed) Ethnography in the Global Education Policyscape. In: BEACH, D.; BAGLEY, C.; SILVA, S. M. da. (ed.). The Wiley Handbook of Ethnography of Education. London: John Wiley \& Sons, 2018. p. 455-477.

LAHIRE, B. Campo. In: CATANI, A. M. et al. (org.). Vocabulário de Bourdieu. Belo Horizonte: Autêntica, 2017. p. 64-66.

LEASK, I. Beyond subjection: notes on the later Foucault and education. Educational Philosophy and Theory, [s. I.], v. 44, n. 1, p. 57-73, 2011.

LEE, H. E. Education without schools: discovering alternatives. Bristol: Policy Press, 2014.

LOPES, A. C.; MACEDO, E. Em defesa das escolas como produtoras de políticas. In: BALL, S. J.; MAGUIRE, M.; BRAUN, A. Como as escolas fazem as políticas: atuação em escolas secundárias. 2. ed. Ponta Grossa: Editora UEPG, 2021. p. 3-18.

MAINARDES, J. Entrevista com o Professor Stephen J. Ball. Olh@res, Guarulhos, v. 3, n. 2, p. 161-171, 2015.

MAINARDES, J. Reflexões sobre o objeto de estudo da política educacional. Laplage em Revista, Sorocaba, v. 4, n. 1, p. 186-201, jan./abr. 2018.

MAINARDES, J. Autoentrevista. In: MAINARDES, J. Alfabetização e prática pedagógica: trajetórias \& vivências, 2021. p. 127-143.

MAINARDES, J.; ALFERES, M. A. Sociologia das políticas educacionais: contribuições de Roger Dale. Atos de Pesquisa em Educação, Blumenau, v. 9, n. 2, p. 392-416, maio/ago. 2014.

MOLLA, T. Critical policy scholarship in education: an overview. Arquivos Analíticos de Políticas Educativas, Arizona, v. 29, n. 2, p. 1-30, 2021.

POWER, S. O detalhe e o macro-contexto: o uso da teoria centrada no Estado para explicar práticas e políticas educacionais. Olhar de Professor, Ponta Grossa, v. 9, n. 1, p. 11-30, jan./jun. 2006.

ROSA; L. O.; FERREIRA, V. S.; SILVA, S. C. V. Elaboração e análise de redes de política. Revista de Estudios Teóricos y Epistemológicos en Política Educativa, Ponta Grossa, v. 5, e2014421, p. 1-12, 2020. 
SAVAGE, G. C. et al. The politics of critical policy sociology: mobilities, moorings and elite networks. Critical Studies in Education, [s. I.], v. 62, n. 3, p. 306-321, 2021.

SAVAGE, G. C. The evolving state of policy sociology. Critical Studies in Education, [s. I.], v. 62, n. 3, p. 275-289, 2021.

SHIROMA, E. O. Redes, experts e a internacionalização de políticas educacionais. Revista de Estudios Teóricos y Epistemológicos em Política Educativa, Ponta Grossa, v. 5, p. 1-22, 2020.

SOUZA, A. R. A pesquisa em Política e Gestão da Educação no Brasil (19982015): atualizando o estado do conhecimento. Educação \& Sociedade, Campinas, v. 40, e0207654, p. 1-21, dez. 2019.

SOUZA, A. R. Política e gestão da educação no Brasil (1998-2015): focalização da pesquisa nas demandas sociais por educação. In: MAINARDES, J. Metapesquisa no campo da Política Educacional. Curitiba: CRV, 2021. 145-167.

STETSENKO, A. Ético-ontoepistemologia ativista: pesquisa e estudo de resistência. In: ANPEd. Ética e pesquisa em educação: subsídios. v. 2. Rio de Janeiro: ANPEd, 2021. p. 1-9.

STREMEL, S. A constituição do campo acadêmico da política educacional no Brasil. 2016. 315 f. Tese (Doutorado em Educação) - Universidade Estadual de Ponta Grossa, Ponta Grossa, 2016.

STREMEL, S.; MAINARDES, J. A constituição do campo acadêmico da política educacional no Brasil: aspectos históricos. Arquivos Analíticos de Políticas Educativas, Arizona, v. 26, p. 1-21, 2018.

WISE, J. M. Assemblage. In: STIVALE, C. J. (ed.). Gilles Deleuze: key concepts. Montreal: McGuill-Queens University Press, 2005. p. 77-87.

YOUDELL, D. Assemblage theory and education policy sociology. In: GULSON, K. N.; CLARKE, M.; PETERSEN, E. B. (ed.). Education policy and contemporary theory: implications for research. Abingdon: Routledge, 2015. p. 110-212.

Recebido em: 21 de julho de 2021

Aprovado em: 30 de agosto de 2021

Publicado em: 24 de setembro de 2021

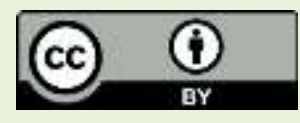

